\title{
Article \\ Indole Derivatives Obtained from Egyptian Enterobacter sp. Soil Isolates Exhibit Antivirulence Activities against Uropathogenic Proteus mirabilis
}

\author{
Mai A. Amer ${ }^{1}, \operatorname{Reham~Wasfi~}^{1}{ }^{\mathbb{D}}$, Ahmed S. Attia $^{2,3, *(\mathbb{D}}$ and Mohamed A. Ramadan ${ }^{2}$ \\ 1 Department of Microbiology and Immunology, Faculty of Pharmacy, October University for Modern Sciences \\ and Arts (MSA), Giza 12451, Egypt; mwahed@msa.edu.eg (M.A.A.); rwasfi@msa.edu.eg (R.W.) \\ 2 Department of Microbiology and Immunology, Faculty of Pharmacy, Cairo University, Cairo 11562, Egypt; \\ Mohamed.abdelhalim@pharma.cu.edu.eg \\ 3 Department of Microbiology and Immunology, School of Pharmacy, Newgiza University, Giza 11341, Egypt \\ * Correspondence: ahmed.attia@pharma.cu.edu.eg
}

Citation: Amer, M.A.; Wasfi, R.; Attia, A.S.; Ramadan, M.A. Indole Derivatives Obtained from Egyptian Enterobacter sp. Soil Isolates Exhibit Antivirulence Activities against Uropathogenic Proteus mirabilis. Antibiotics 2021, 10, 363. https:// doi.org/10.3390/antibiotics10040363

Academic Editor: Eliana De Gregorio

Received: 10 March 2021

Accepted: 26 March 2021

Published: 29 March 2021

Publisher's Note: MDPI stays neutral with regard to jurisdictional claims in published maps and institutional affiliations.

Copyright: (c) 2021 by the authors. Licensee MDPI, Basel, Switzerland. This article is an open access article distributed under the terms and conditions of the Creative Commons Attribution (CC BY) license (https:/ / creativecommons.org/licenses/by/ $4.0 /)$.

\begin{abstract}
Proteus mirabilis is a frequent cause of catheter associated urinary tract infections (CAUTIs). Several virulence factors contribute to its pathogenesis, but swarming motility, biofilm formation, and urease activity are considered the hallmarks. The increased prevalence in antibiotic resistance among uropathogens is alarming and requires searching for new treatment alternatives. With this in mind, our study aims to investigate antivirulence activity of indole derivatives against multidrug resistant P. mirabilis isolates. Ethyl acetate (EtOAc) extracts from Enterobacter sp. (rhizobacterium), isolated from Egyptian soil samples were tested for their ability to antagonize the virulence capacity and biofilm activity of $P$. mirabilis uropathogens. Extracts of two Enterobacter sp. isolates (coded Zch127 and Cbg70) showed the highest antivirulence activities against $P$. mirabilis. The two promising rhizobacteria Zch127 and Cbg70 were isolated from soil surrounding: Cucurbita pepo (Zucchini) and Brassica oleracea var. capitata L. (Cabbage), respectively. Sub-minimum inhibitory concentrations (Sub-MICs) of the two extracts showed potent antibiofilm activity with significant biofilm reduction of ten P. mirabilis clinical isolates $(p$-value $<0.05)$ in a dose-dependent manner. Interestingly, the Zch127 extract showed anti-urease, anti-swarming and anti-swimming activity against the tested strains. Indole derivatives identified represented key components of indole pyruvate, indole acetamide pathways; involved in the synthesis of indole acetic acid. Additional compounds for indole acetonitrile pathway were detected in the Zch127 extract which showed higher antivirulence activity. Accordingly, the findings of the current study model the feasibility of using these extracts as promising antivirulence agent against the P. mirabilis uropathogens and as potential therapy for treatment of urinary tract infections (UTIs).
\end{abstract}

Keywords: Proteus mirabilis; microbial indole derivatives; anti-urease, anti-biofilm; anti-swarming; Enterobacter sp.

\section{Introduction}

Urinary tract infections (UTI) are the major cause of healthcare associated infections accounting for $40 \%$ of all hospital acquired infections. Catheter associated urinary tract infections (CAUTI) represent approximately $80 \%$ of Healthcare associated UTIs [1]. Bacteria that belong to the family Enterobacteriaceae are the most frequent causative agent of UTIs. Clinically, Proteus mirabilis is the most common cause of complicated urinary tract infections, particularly in patients suffering from long-term catherization. These infections are complicated by catheter encrustation and blockage resulting from the ability of this bacterium to produce crystalline biofilm [2].

$P$. mirabilis is an opportunistic pathogen, which is widely spread in the environment, mainly found in water, soil, and the gastrointestinal tracts of humans and animals. 
P. mirabilis uses a diverse set of virulence factors to access and colonize the host urinary tract. These virulence factors include flagella, fimbriae, urease enzyme, capsule polysaccharide, and efflux pump resulting in crystalline biofilm formation [3]. P. mirabilis UTIs are often very persistent and difficult to be treated due to its intrinsic resistance to polymyxin, tetracycline, and nitrofurazone [2], as well as the emergence of multidrug resistant strains [4]. CAUTI formed by P. mirabilis are difficult to be treated because of their ability to form dense crystalline biofilm which offers protection for the bacterial cells within the matrix from antibiotics and immune system [3]. P. mirabilis has been shown to enter the viable but non culturable state (VBNC) under conditions of high osmotic pressure and yet retaining virulence [5]. All the previously mentioned reasons made searching for new alternatives for antimicrobial agents crucial.

Antivirulence compounds attract increasing interest recently because they affect bacterial virulence without creating selection pressure on the microorganisms and thus reduce the development of antibiotic resistance. Inhibiting virulence factors could attenuate bacterium pathogenicity, and consequently enable the host immune system to successfully combat the pathogen [6]. In the recent years, indole has been gaining much attention as an intercellular, interspecies, and interkingdom signaling molecule [7]. Several studies have shown that some indole derivatives can inhibit the virulence activity of several bacteria including Escherichia coli O157:H7, Pseudomonas aeruginosa, Salmonella enterica serovar Typhimurium, and Staphylococcus aureus [6,8-13]. Another study carried out by Palaniyandi and co-workers reported that phytohormones metabolites produced by rhizobacteria was found to protect host plant against pathogens [14]. Thus, the aim of this study was exploring the antibiofilm and antivirulence activities of natural metabolites derived from indole, produced by rhizobacteria, against clinical isolates of $P$. mirabilis and up to the best of our knowledge this is the first report on the antivirulence effect of these metabolites on P. mirabilis.

\section{Results and Discussion}

2.1. Some Rhizobacteria Enterobacter sp. Isolates Exhibit High Indole Production Coupled with Potential Antivirulence Activity against P. mirabilis

Out of twelve collected soil samples from different locations in Egypt, a total of 137 bacterial isolates were collected. Sixty isolates were indole producer as detected by the positive color reaction with Salkowski's reagent and among them 13 isolates showed highest indole production (Table S1). Ethyl acetate extracts of the highest indole producing isolates were tested for their antivirulence activity against $P$. mirabilis (P1 isolate). Competition between microorganisms living in the environment drives them to produce a wide range of secondary metabolites to aid their survival in the presence of other microbes [7], hence they become a source for potential antivirulent agents.

Two rhizobacterial isolates, coded as "Cbg70" and "Zch127", were selected for further study due to their potent antivirulence activity, including antibiofilm, anti-swarming and anti-urease activities, against $P$. mirabilis isolate (P1) compared to other tested extracts (Figure 1). The "Cbg70" and "Zch127" were isolated from soil surrounding the roots of Brassica oleracea var. capitata L. (Cabbage) and Cucurbita pepo (Zucchini), respectively. Cruciferous (or Brassica) vegetables, including cauliflower, brussels, broccoli, and cabbage, are rich sources for indole derivatives $[15,16]$, and previous studies have revealed that indole-3-carbinol and 3,3'-bismethyl indole from cruciferous vegetables have antiviral, antimicrobial and anticancer activities [16,17]. Indole derivatives derived from natural sources such as cruciferous plants and actinomycetes as Rhodococcus sp. BFI 332 were reported to have antibiofilm activity against Escherichia coli, Staphylococcus aureus, and Pseudomonas aeruginosa $[9,10,12]$. 


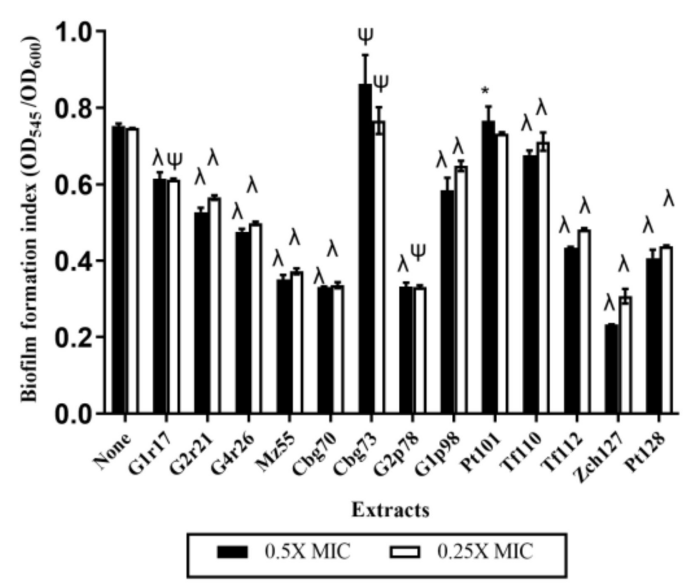

A

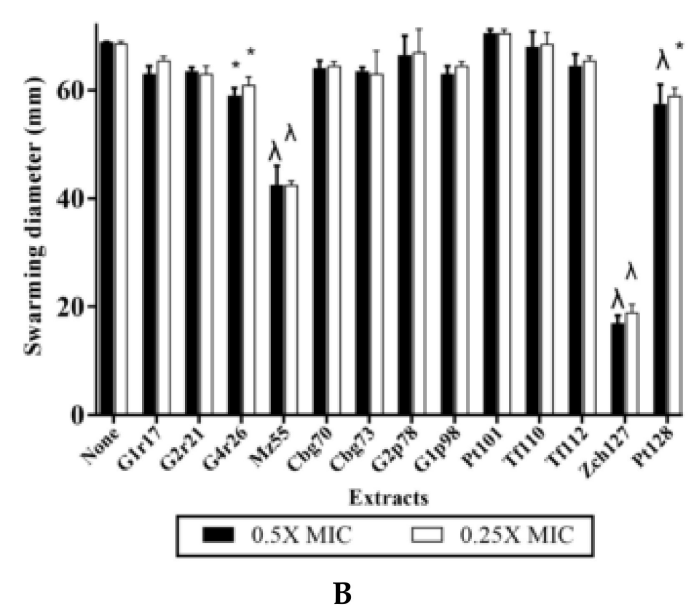

B

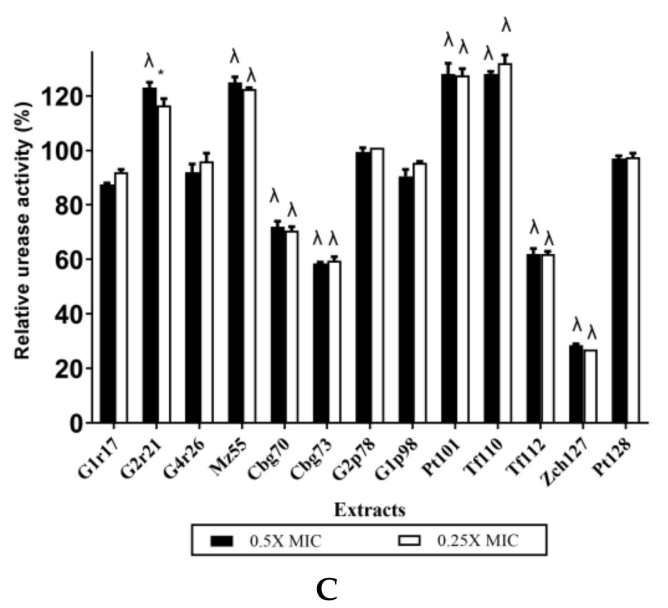

Figure 1. Antivirulence activity of 13 bacterial culture extracts on P. mirabilis P1 isolate. The effect of $0.5 \mathrm{X}$ of minimum inhibitory concentration (MIC) (Extracts no. G1r21, Cbg73, G2p78: 1.25 mg/mL, G1r17, G1p98, Zch127: 0.625 mg/mL extracts no. Mz55, Tf110, Tf112, Pt128: $0.312 \mathrm{mg} / \mathrm{mL}$, extracts no. Pt101: $0.156 \mathrm{mg} / \mathrm{mL}$ and extracts G4r26, Cbg70: $0.08 \mathrm{mg} / \mathrm{mL}$ ) and $0.25 \mathrm{X}$ MIC of the bacterial culture extracts containing indole derivatives on P. mirabilis isolate P1 (A) Normalized biofilm formation, (B) Diameter of swarming motility, and (C) Relative urease activity, where the values were obtained in the absence of extracts after $3 \mathrm{~h}$ of incubation were set as $100 \%$, and all other values were expressed relative to this value. Data represents the mean of at least 3 biological replicas. Statistical analysis using two-way ANOVA, which was followed by multiple comparisons test with a significance level at ${ }^{*} p<0.05 ;{ }^{\psi} p<0.01 ;{ }^{\lambda} p<0.001$.

Isolates of Cbg70 and Zch127 were identified by $16 \mathrm{~s} r R N A$ gene sequencing, up to the genus level, as Enterobacter sp. Enterobacter sp. has been previously shown to be abundant in the soil samples [18-20]. The phylogenetic tree of the two selected strains and highly similar strains in the NCBI database was constructed using Mega 6.0 (Figure S1). The two isolated strains were found to belong to the same clade and most of the phylogenetically related strains to these isolates were previously recovered from soil samples as reported in the NCBI database.

\subsection{Half MICs of Cbg70 and Zch127 Have no Inhibitory Effect on Growth of P. mirabilis}

The minimum inhibitory concentrations (MICs) of the Cbg70 and Zch127 culture supernatant extracts against the ten multidrug resistant $P$. mirabilis isolates were 0.16 and $1.25 \mathrm{mg} / \mathrm{mL}$, respectively. The effect of half MIC of extracts on the growth of $P$. mirabilis isolates showed no significant $(p>0.05)$ inhibitory effect compared with the control using two-way ANOVA followed by multiple comparisons test (Figure S2 and S3). The average of cell growth of the P. mirabilis isolates in the presence of half MIC of extracts at different time points were shown in Figure 2. 


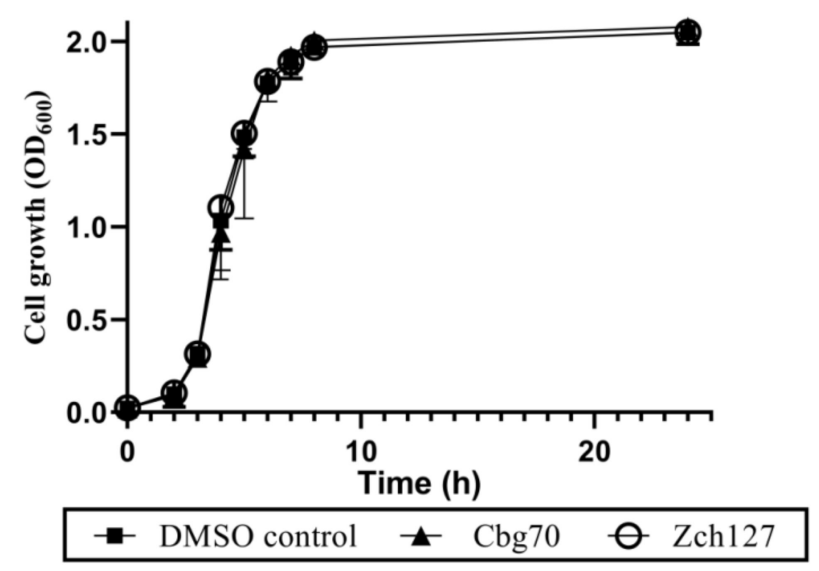

Figure 2. Effect of Enterobacter sp. culture supernatant extracts on bacterial growth of P. mirabilis. Growth of Proteus mirabilis isolates under the effect of sub-minimum inhibitory concentrations (sub-MIC) (0.5X MIC) concentrations of Cbg70 $(0.08 \mathrm{mg} / \mathrm{mL})$ and Zch127 $(0.6 \mathrm{mg} / \mathrm{mL})$ extracts at different time points measured as turbidity $\left(\mathrm{OD}_{600} \mathrm{~nm}\right)$ while shaking at $250 \mathrm{rpm}$. Bacterial culture supplemented with DMSO in the same concentration as extract served as DMSO control. Each experiment was performed using three different cultures for each isolate, and the average data of the ten isolates is shown.

\subsection{Sub MIC Concentrations of Cbg70 and Zch127 Extracts Significantly Inhibit P. mirabilis Biofilm Formation}

Tested $P$. mirabilis isolates showed variable biofilm forming ability, where $70 \%$ of isolates were strong and $30 \%$ were moderate biofilm forming. The indole extract from the selected Enterobacter strains showed antibiofilm activity against $P$. mirabilis reaching up to $65-80 \%$ reduction and the effect was concentration dependent. Significant reduction ( $p$-value $<0.05)$ in biofilm biomass was observed among all the treated P. mirabilis isolates using 0.5X MIC of the Cbg70 and Zch127 extracts (Figure 3). Similar reduction percentage was observed by Lee et al. [10] using actinomycete Rhodococcus sp. BFI 332 indole containing extracts that inhibited biofilm formation in E. coli O157:H7 by 70\%. The antibiofilm effect of indole derivatives could be attributed to their effect in decreasing curli production [9] or their role in signaling between bacterial cells at the intra and inter species levels [8].

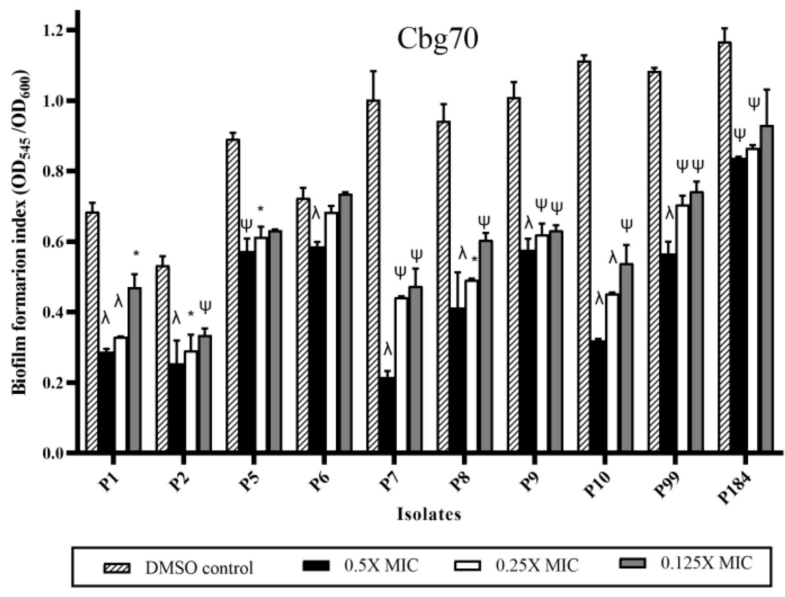

A

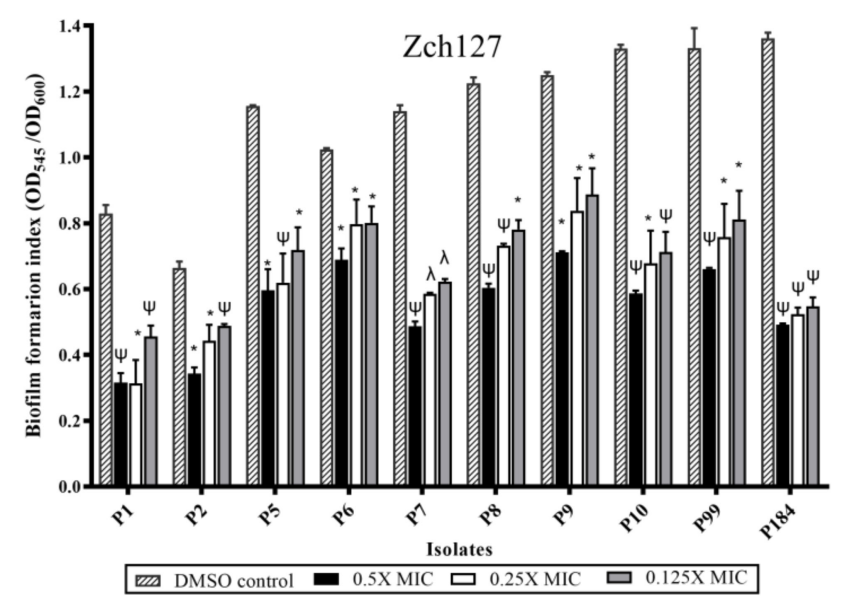

B

Figure 3. Inhibitory effect of Enterobacter sp. culture supernatant on biofilm formation of $P$. mirabilis isolates. Average biofilm formation index of P. mirabilis isolates following treatment with sub- MICs of the indole extracts: DMSO control (striped bars), at 0.5X MIC (black bars), 0.25X MIC (white bars), and 0.125X MIC (grey bars): (A) Culture supernatant of extract Cbg70 at concentrations ranging from $(20$ to $80 \mu \mathrm{g} / \mathrm{mL})$, (B) Culture supernatant of extract Zch127 at concentrations ranging from ( 0.15 to $0.6 \mathrm{mg} / \mathrm{mL}$ ), Data represents the mean of at least 3 biological replicates, and error bars show standard error of the mean. Statistically difference was determined by student's $t$-test ${ }^{*} p<0.05 ;{ }^{\psi} p<0.01{ }^{\lambda} p<0.001$ compared with DMSO control. 


\subsection{Indole Extract Zch 127 Inhibited the Swimming and Swarming Motility of P. mirabilis}

Sub-minimum inhibitory concentrations (Sub-MICs) of the crude extract "Zch127" showed inhibitory effect on the swarming and swimming motilities of the P. mirabilis isolates without any effect on growth (Figure 4). The anti-swarming and anti-swimming effects were concentration dependent (Figures S4-S6), while Cbg70 extract showed no effect on bacterial motility (data not shown). Flagellar-mediated swimming motility is associated with biofilm formation because it enables the bacteria to reach substratum and start the attachment to surface [21]. Studies showed that antibiofilm activity of some natural compounds is coupled with its ability to inhibit the swarming differentiation [22,23].

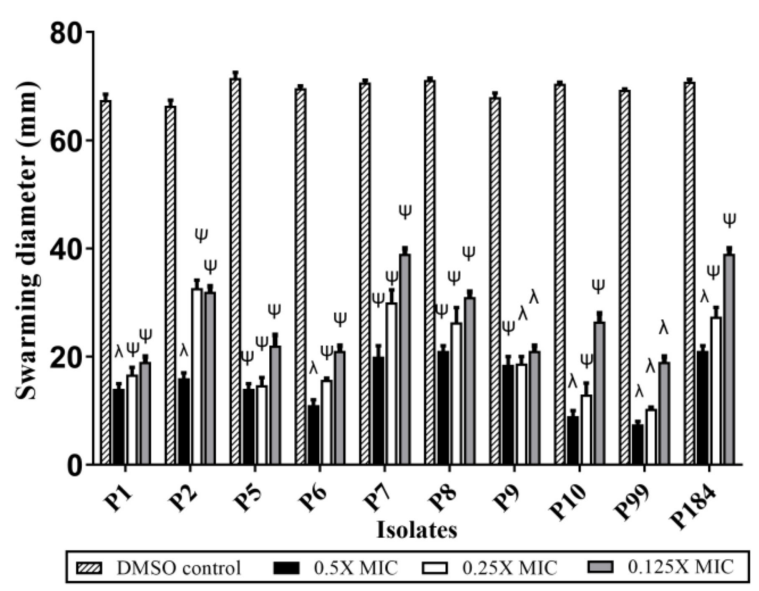

A

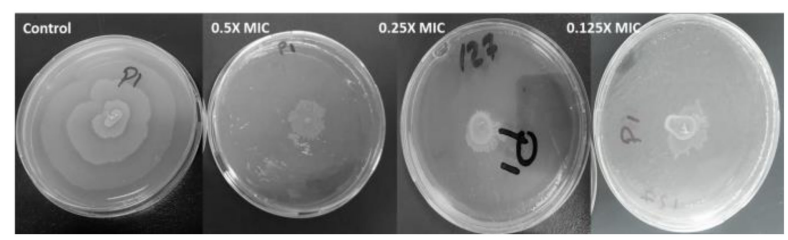

C

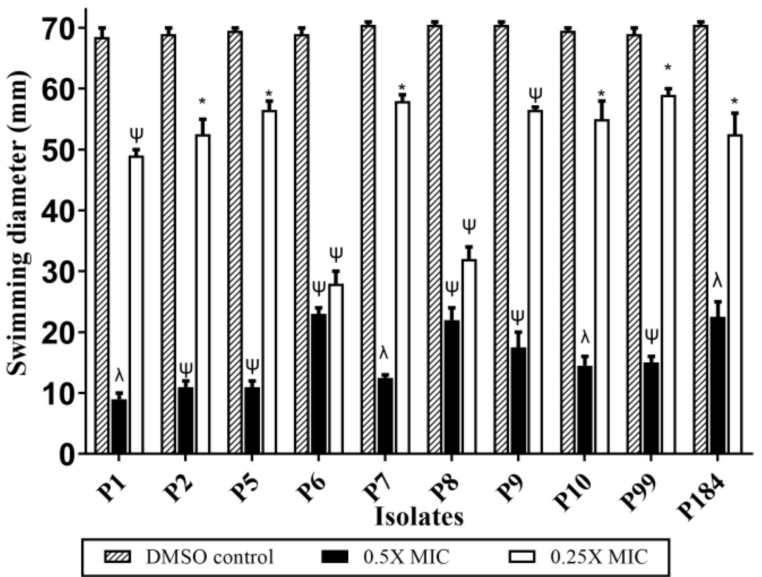

B

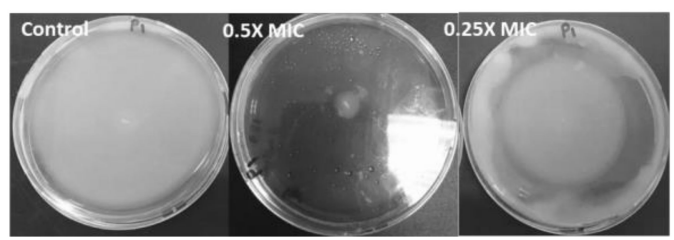

D

Figure 4. Inhibitory Effect of Zch127 culture extract on motility. The effect of Zch127 at sub-MICs on the motility of 10 P. mirabilis isolates (A) Swarming motility at 0.125X, 0.25X, and 0.5X MIC; (B) Swimming motility at 0.25X and 0.5X MIC, Data represents the mean of 3 experiments, and error bars shows standard error. Statistical difference was determined by student's $t$-test, ${ }^{*} p<0.05 ;{ }^{*} p<0.01 ;{ }^{\lambda} p<0.001$ compared with DMSO control; (C) Representative images of the effect of extract Zch127 on swarming motility of P. mirabilis isolate P1; (D) Representative images of the effect of extract Zch127 on swimming motility of $P$. mirabilis isolate P1.

\subsection{Inhibitory Effect of Zch127 Crude Extract on the Urease Activity of P. mirabilis}

In Christensen's medium, untreated P. mirabilis was able to utilize the urea as the sole source of nitrogen, thus producing an amount of ammonia sufficient to change the color of the $\mathrm{pH}$ indicator (phenol red) in the medium and that was measured spectrophotometrically after $3 \mathrm{~h}$ of incubation. The Cbg70 extract showed variable effect on the urease activity of the tested P. mirabilis isolates. Significant reduction $(p<0.05)$ in urease activity was observed in 4 isolates, only namely P5, P8, P99, and P184 by 90\%, 34\%, 39\%, and 38\%, respectively, compared to untreated control (Figure 5A). Treatment of P. mirabilis isolates with the extract Zch127 significantly $(p<0.05)$ reduced the urease activity after $3 \mathrm{~h}$ of incubation in all isolates and that effect was concentration dependent (Figure 5B). 

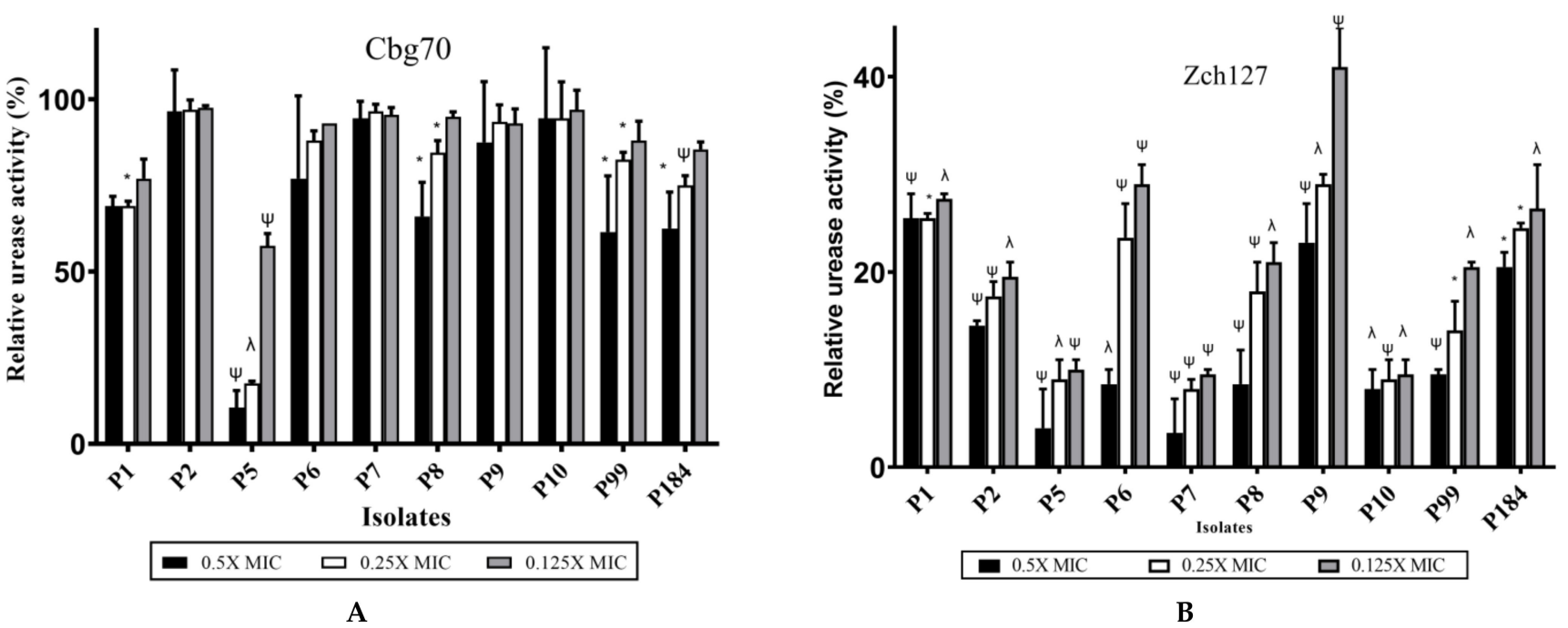

Figure 5. Effect of crude supernatant extracts of Cbg70 and Zch127 on urease activity. The relative urease activity of the P. mirabilis isolates in the presence of sub-MICs of extracts: (A) Cbg70; and (B) Zch127, at different concentrations (0.5X, $0.25 \mathrm{X}$ and $0.125 \mathrm{X} \mathrm{MIC})$. The values were obtained in the absence of extract after $3 \mathrm{~h}$ of incubation were set at $100 \%$, and all other values were expressed relative to this value. The data represents the means of three independent experiments and error bars show standard error of the mean. Statistical difference was determined by student's $t$-test ${ }^{*} p<0.05 ;{ }^{\psi} p<0.01$; $\lambda p<0.001$ compared with DMSO control.

\subsection{The Effect of Cbg70 and Zch127 Crude Extracts on the Antibiotic Sensitivity of P. mirabilis}

The effect of combining the extracts Cbg70 and Zch127, at sub-MICs, was assayed with three antibiotics: ceftriaxone, ciprofloxacin, and amikacin. The extract Zch127 at sub-MIC showed synergistic activity with the antibiotics: ceftriaxone and amikacin with most of the tested isolates. The same extract showed antagonistic effect with ciprofloxacin against $40 \%(4 / 10)$ of isolates (Table 1). The effect of the extract Cbg 70 was variable with different antibiotics with the majority of these effects were antagonistic to the effect of antibiotic (Table 1). Some small molecules have been previously reported to cause synergistic activity with antibiotics against pathogenic bacteria [24]. Previous studies reported change in antibiotic resistance in presence of indole and indole derivatives with different microorganisms. The change was variable according to the bacterial strain, indole derivatives $[6,25,26]$, and the mechanism underlying antibiotic resistance [27]. 
Table 1. Fold changes in minimum inhibitory concentration of selected antibiotics in presence of indole derivatives crude extracts at sub-MIC against Proteus mirabilis isolates.

\begin{tabular}{|c|c|c|c|c|c|c|}
\hline Antibiotic & $\begin{array}{c}\text { Isolate } \\
\text { No. }\end{array}$ & MIC & $\begin{array}{l}\text { MIC with } \\
\text { Extract } \\
\text { Cbg70 }^{\text {a }}\end{array}$ & $\begin{array}{c}\text { Fold Change } \\
\text { in MIC with } \\
\text { Cbg70 }\end{array}$ & $\begin{array}{c}\text { MIC with } \\
\text { Extract } \\
\text { Zch127 }^{\text {b }}\end{array}$ & $\begin{array}{c}\text { Fold Change } \\
\text { in MIC with } \\
\text { Zch127 }\end{array}$ \\
\hline \multirow{10}{*}{ Ceftriaxone } & P1 & $64(\mathrm{R})$ & 32(R) & $-2 X$ & 16(R) & $-4 X$ \\
\hline & P2 & 16(R) & $16(\mathrm{R})$ & - & $4(\mathrm{R})$ & $-4 X$ \\
\hline & P5 & 16(R) & $16(\mathrm{R})$ & - & $8(\mathrm{R})$ & $-2 X$ \\
\hline & P6 & 32(R) & $32(\mathrm{R})$ & - & $32(\mathrm{R})$ & - \\
\hline & P7 & $4(\mathrm{R})$ & $8(\mathrm{R})$ & $2 X$ & $4(\mathrm{R})$ & - \\
\hline & P8 & $128(\mathrm{R})$ & $128(\mathrm{R})$ & - & 64(R) & $-2 X$ \\
\hline & P9 & 64(R) & $64(\mathrm{R})$ & - & 64(R) & - \\
\hline & P10 & $8(\mathrm{R})$ & $8(\mathrm{R})$ & - & $8(\mathrm{R})$ & - \\
\hline & P99 & $2(\mathrm{I})$ & $1(\mathrm{~S})$ & $-2 X$ & $1(\mathrm{~S})$ & $-2 X$ \\
\hline & P184 & $16(\mathrm{R})$ & 16(R) & - & $8(\mathrm{R})$ & $-2 x$ \\
\hline \multirow{10}{*}{ Ciprofloxacin } & P1 & 16(R) & $16(\mathrm{R})$ & - & $16(\mathrm{R})$ & - \\
\hline & P2 & $16(\mathrm{R})$ & $32(\mathrm{R})$ & $2 X$ & 64(R) & $4 X$ \\
\hline & P5 & $32(\mathrm{R})$ & 64(R) & $2 X$ & 64(R) & $2 X$ \\
\hline & P6 & $32(\mathrm{R})$ & 64(R) & $2 X$ & $32(\mathrm{R})$ & - \\
\hline & P7 & $4(\mathrm{R})$ & $8(\mathrm{R})$ & $2 X$ & $8(\mathrm{R})$ & $2 X$ \\
\hline & P8 & 64(R) & 64(R) & - & 64(R) & - \\
\hline & P9 & 64(R) & 64(R) & - & 64(R) & - \\
\hline & P10 & $16(\mathrm{R})$ & $8(\mathrm{R})$ & $-2 X$ & $32(\mathrm{R})$ & $2 X$ \\
\hline & P99 & $8(\mathrm{R})$ & $8(\mathrm{R})$ & - & $8(\mathrm{R})$ & - \\
\hline & P184 & 64(R) & $32(\mathrm{R})$ & $-2 X$ & $64(\mathrm{R})$ & - \\
\hline \multirow{10}{*}{ Amikacin } & P1 & $4(S)$ & $4(S)$ & - & $0.5(S)$ & $-8 \mathrm{X}$ \\
\hline & P2 & $8(S)$ & $8(S)$ & - & $2(S)$ & $-4 X$ \\
\hline & P5 & $8(S)$ & $16(S)$ & $2 X$ & $1(S)$ & $-8 X$ \\
\hline & P6 & $8(S)$ & $16(S)$ & $2 X$ & $2(S)$ & $-4 X$ \\
\hline & P7 & $4(\mathrm{~S})$ & $8(S)$ & $2 X$ & $0.5(\mathrm{~S})$ & $-8 X$ \\
\hline & P8 & $8(\mathrm{~S})$ & $32(\mathrm{I})$ & $4 X$ & $0.5(\mathrm{~S})$ & $-16 X$ \\
\hline & P9 & $16(\mathrm{~S})$ & $16(S)$ & - & $0.5(\mathrm{~S})$ & $-32 X$ \\
\hline & P10 & $4(S)$ & $4(S)$ & - & $4(\mathrm{~S})$ & - \\
\hline & P99 & $4(S)$ & $16(S)$ & $4 X$ & $1(S)$ & $-4 X$ \\
\hline & P184 & $8(S)$ & $32(S)$ & $4 X$ & $0.5(\mathrm{~S})$ & $-16 X$ \\
\hline
\end{tabular}

a sub-MIC $=0.08 \mathrm{mg} / \mathrm{mL}^{\mathrm{b}}$ sub-MIC $=0.6 \mathrm{mg} / \mathrm{mL}$. (-) before fold of change denotes decrease in MIC. Results of MIC was interpreted according to CLSI [28] into Resistant (R), Intermediate (I), Sensitive (S).

\subsection{Identification of Indole Derivatives in the Crude Extracts by LC-MS Analysis}

LC-MS was employed to identify the bioactive compounds in the ethyl acetate (EtOAc) fraction of extracts Cbg70 and Zch127 after four days of incubation. The analysis was carried out in the positive and the negative modes (Figure S7). Compounds were identified based on their molecular ion mass, mass fragmentation pattern, and absorption spectra. As shown in Table 2 and Figures S8-S11, the described spectrum was indicative for the presence of eight indole derivatives in the extract Cbg70 where indole acetic acid (IAA), indole-3-ethanol (TOL), and indole-3-acetaldehyde were detected in both modes, tryptophan (Trp), indole-3-pyruvic acid (IPA) and indole-3-aldehyde were detected in the positive mode while indole-3-propionic acid and indole-3-acetamide were detected in the negative mode. Indole derivatives in Zch127 extract were ten, where IAA, TOL, IPA and 3-methyl indole were detected in both modes, Trp and indole-3-acetamide were detected in the negative mode, while indole-3-lactic acid, indole-3-acetaldehyde, indole-3-carboxylic acid, and indole-3-acetonitrile were detected in the positive mode. 
Table 2. LC-MS identified peaks of the extract from isolates Cbg70 and Zch127and their fragmentation pattern.

\begin{tabular}{|c|c|c|c|}
\hline \multicolumn{4}{|c|}{ Cbg70 } \\
\hline * Rt (min) & Peak No. & Mass (m/z) Fragmentation & Indole Derivative \\
\hline 2.87 & 13 & $\begin{array}{c}205[\mathrm{M}+\mathrm{H}]^{+} \\
(205,159,144,143,130,117,115)\end{array}$ & Tryptophan \\
\hline 8.01 & 30 & $176[\mathrm{M}+\mathrm{H}]^{+}(176,130,103)$ & Indole-3-acetic acid (IAA) \\
\hline 8.01 & 33 & $162[\mathrm{M}+\mathrm{H}]^{+}(162,144,143,117,115)$ & Indole-3- ethanol (TOL) \\
\hline 8.3 & 33 & $146[\mathrm{M}+\mathrm{H}]^{+}(146,118,117,91)$ & Indole-3-aldehyde \\
\hline 11.2 & 45 & $205[\mathrm{M}+2 \mathrm{H}]]^{+}(205,142,139,117)$ & Indole-3-pyruvic acid \\
\hline 11.88 & 48 & $198[\mathrm{M}+\mathrm{K}]^{+}(198,133,118)$ & Indole-3-acetaldehyde (IAld) \\
\hline 1.07 & 3 & $188[\mathrm{M}-\mathrm{H}]^{-}(188,128,59)$ & Indole-3-propionic acid \\
\hline 4.62 & 17 & $158[\mathrm{M}-\mathrm{H}]^{-}(158,130,117)$ & Indole-3- acetaldehyde \\
\hline 6.76 & 28 & $174[\mathrm{M}-\mathrm{H}]^{-}(174,130,128)$ & Indole-3-acetic acid (IAA) \\
\hline 7.43 & 31 & $160[\mathrm{M}-\mathrm{H}]^{-}(160,130)$ & Indole-3-ethanol (TOL) \\
\hline 7.77 & 31 & $173[\mathrm{M}-\mathrm{H}]^{-}(174,131,130,111)$ & Indole-3-acetamide \\
\hline \multicolumn{4}{|c|}{ Zch127 } \\
\hline Rt (min) & Peak No. & Mass $(\mathrm{m} / \mathrm{z})$ Fragmentation & Indole Derivative \\
\hline 1.31 & 10 & $132[\mathrm{M}+\mathrm{H}]^{+}(132,86,69)$ & 3-methyl indole (skatole) \\
\hline 1.98 & 7 & $162[\mathrm{M}+\mathrm{H}]^{+}(162,144,120)$ & $\begin{array}{l}\text { Indole-3-carboxylic acid } \\
\text { (I3CA) }\end{array}$ \\
\hline 6.66 & 19 & $176[\mathrm{M}+\mathrm{H}]^{+}(176,130,118,103,77)$ & Indole-3-acetic acid (IAA) \\
\hline 6.93 & 19 & $245[\mathrm{M}+\mathrm{K}]^{+}(245,174,173,130)$ & Indole-3-lactic acid (ILA) \\
\hline 8.01 & 26 & $162[\mathrm{M}+\mathrm{H}]^{+}(162,144,143,117,115)$ & Indole-3-ethanol (TOL) \\
\hline 9.04 & 37 & $205[\mathrm{M}+2 \mathrm{H}]+(205,158,130,87,72)$ & Indole-3-pyruvic acid \\
\hline 13.1 & 76 & $199[\mathrm{M}+\mathrm{H}+\mathrm{K}]^{+}(199,133,117)$ & Indole-3- acetaldehyde \\
\hline 14.46 & 86 & $196[\mathrm{M}+\mathrm{H}+\mathrm{K}]^{+}(196,131,117,79)$ & Indole-3-acetonitrile \\
\hline 2.84 & 9 & $\begin{array}{c}203[\mathrm{M}-\mathrm{H}]^{-}(203,158,146,142 \\
132,118,116)\end{array}$ & Tryptophan \\
\hline 6.27 & 18 & $173[\mathrm{M}-\mathrm{H}]^{-}(173,143,130)$ & Indole-3-acetamide (IAM) \\
\hline 8.72 & 50 & $202[\mathrm{M}-\mathrm{H}]-(202,158,130)$ & Indole-3-pyruvic acid \\
\hline 16.21 & 97 & $130[\mathrm{M}-\mathrm{H}]-(130,115.4)$ & 3-methyl indole (skatole) \\
\hline
\end{tabular}

\subsection{Identification and Verification of Indole Compounds in the Extracts Using HPLC}

HPLC analysis was done to identify and quantify indole derivatives precisely. Several authentic indole derivatives (100 $\mu \mathrm{M}$ each, except IPA at $200 \mu \mathrm{M})$ were separated and their peaks were detected by HPLC using a $\mathrm{C}_{18}$ reverse column (Figure 6). Under the optimum conditions of analysis, the retention times of tryptophan (Trp), tryptamine (TAM), indole-3acetamide (IAM), indole-3-lactic acid (ILA), indole-3-acetic acid (IAA), indole-3-acetonitrile (IAN), and indole-3-pyruvic acid (IPA) were 4.04, 4.25, 8.2, 11.9, 18, 24.8, and $36.4 \mathrm{~min}$, respectively. Extracts from the selected rhizobacterial cultures of Enterobacter sp. isolates (Cbg70 and Zch127) in trypticase soy broth medium supplemented with $0.5 \mathrm{mM}$ Trp were analyzed using HPLC and indole derivatives were identified and quantified after two and four days of incubation. Typically, 14-15 peaks, were identified and confirmed based on their retention time (Rt) and co-elution with authentic standards (Figure 6A). When comparing extract of the isolate $\mathrm{Cbg} 70$ to the authentic standards (Figure 6B), it showed peaks 4, 8, 10, 12, and 14 that co-eluted with Trp, IAM, ILA, IAA, and IPA, respectively, with variable concentrations. The bacterial culture of isolate Zch127 was analyzed by HPLC (Figure 6C). Peaks 4, 8, 10, 12, 13, and 14 co-eluted with Trp, IAM, ILA, IAA, IAN, and IPA, respectively. Other peaks remain to be determined. Indole acetic acid concentrations increased by increasing time of incubation and consumption of more tryptophan by the tested isolates (Table 3). 

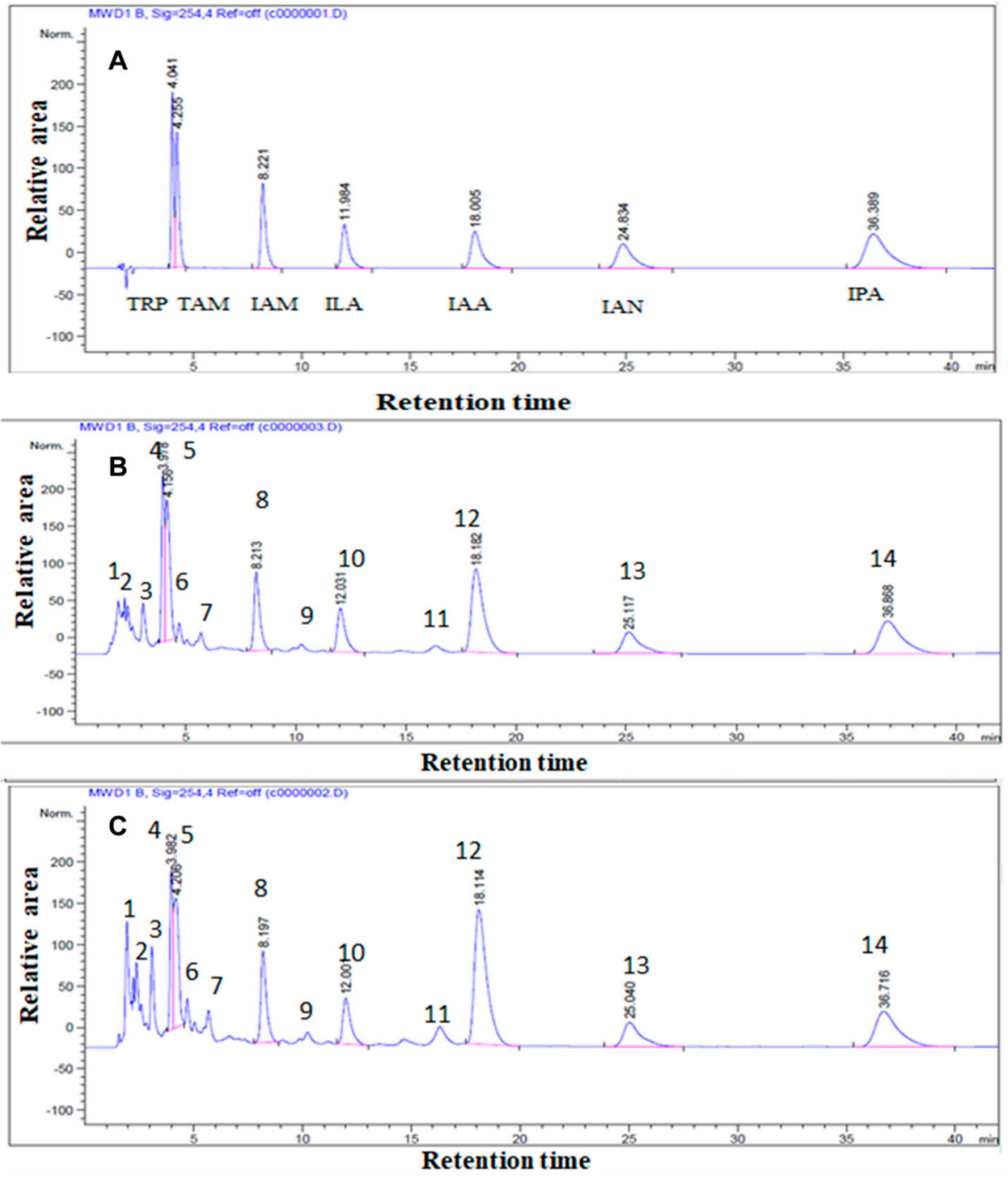

Figure 6. HPLC chromatograms of the authentic indole compounds (A) and the ethyl acetate extract containing indole compounds from (B): isolate Cbg70 and (C): isolate Zch127 after 4 days of incubation.

Table 3. The concentration $(\mu \mathrm{M})$ of the identified compounds, in extracts Cbg70 and Zch 127 after 2 and 4 days of incubation, using HPLC confirmed by co-elution with the authentic indole derivative.

\begin{tabular}{cccccc}
\hline Compound & Rt & $\begin{array}{c}\text { Cbg70 } \\
\text { 2 days }(\boldsymbol{\mu M})\end{array}$ & $\begin{array}{c}\text { Cbg70 } \\
\text { 4 days }(\boldsymbol{\mu M})\end{array}$ & $\begin{array}{c}\text { Zch127 } \\
\text { 2 days }(\boldsymbol{\mu M})\end{array}$ & $\begin{array}{c}\text { Zch127 } \\
\text { 4 days }(\boldsymbol{\mu M})\end{array}$ \\
\hline Tryptophan & 4.040 & 44.226 & 36.648 & 40.798 & 9.866 \\
IAM & 8.221 & 22.800 & 25.120 & 19.120 & 22.880 \\
ILA & 11.984 & 21.465 & 24.148 & 24.045 & 10.939 \\
IAA & 18.005 & 99.915 & 199.680 & 117.241 & 321.278 \\
IAN & 24.830 & 0 & 0 & 4.407 & 19.729 \\
IPA & 36.380 & 19.428 & 24.390 & 24.978 & 7.232 \\
\hline
\end{tabular}

Intermediates that belong to different pathways were detected in both extracts, including IAM, which is the key intermediate in the indole acetamide pathway, in addition to TOL, indole-3-acetaldehyde (IaAld), IPA, and ILA, which are the products in indole pyruvic acid pathway, whereas IAN (the product of indole acetonitrile pathway) was detected only in extract Zch127 (Figure 7). 


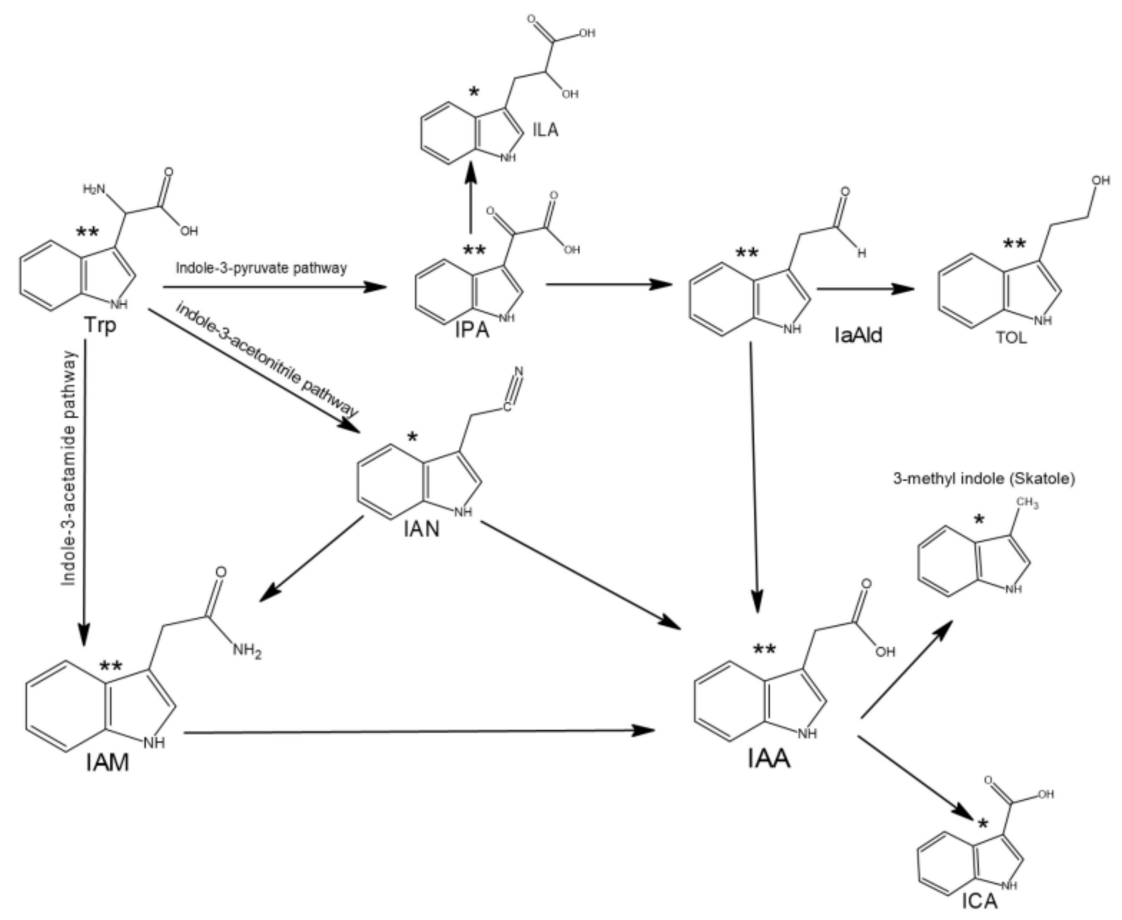

Figure 7. Proposed pathways of indole acetic acid (IAA) synthesis in the supernatant extracts of the Enterobacter sp. cultures, where ${ }^{* *}$ means that the compound was detected in both cultures while * means that it was detected in the extract of Zch127 culture only, where Trp: tryptophan, IAM: indole-3-acetamide, IAN: indole-3-acetamide, IPA: indole-3-pyruvic acid, ILA: indole-3-lactic acid, IaAld: indole-3-acetaldehyde, TOL: indole-3-ethanol and ICA: indole-3-carboxylic acid.

The presence of multiple pathways for tryptophan catabolism in the same microorganism was reported previously in Rubrivivax benzoatilyticus [29] and Pseudomonas putida [30]. Genome of E. cloacae subsp. cloacae NCTC 9394 and E. cloacae ECNIH5 had been shown to possess the ipdC gene (The key gene for indole pyruvate pathway) and the iaaH gene (The key gene of indole acetamide pathway), nitrilase enzyme which acts on indole-3acetonitrile (The key gene of indole acetonitrile pathway) was previously reported in the genome of Enterobacter cloacae subsp. cloacae ATCC 13047 [31] which confirms the presence of multiple pathways for IAA biosynthesis in these bacteria. Indole 3-pyruvic acid pathway in E. cloacae was reported in previous studies [20,32,33]. Interestingly, the extract Zch127 showed higher antivirulence activity against tested isolates compared to Cbg70 which could be attributed to the presence of the three unique compounds IAN, methyl indole and I3CA. A previous study has revealed the high antibiofilm activity of IAN compared to other indole derivatives against pathogenic bacteria such as Escherichia coli O157:H7 and P. aeruginosa [9]. 2-methylindole (skatole), reduced biofilm formation of EHEC O157:H7 (ATCC 43894) by 52\% [13]. Previous studies have reported the detection of enzymes involved in indole acetonitrile pathway in plant associated bacteria [34,35].

\subsection{Effect of Synthetic IAA and IAN on P. mirabilis Virulence Traits}

The antivirulence activity of two of the detected compounds in the culture extract was confirmed by using synthetic standards against $P$. mirabilis isolates. The two compounds were IAA, detected in high concentration in the two extracts, and IAN, detected in Zch127 extract only. The antivirulence assays were performed using IAA and IAN in a concentration of $50 \mu \mathrm{g} / \mathrm{mL}$ which had no significant inhibitory effect on cell growth. Both IAA and IAN caused significant reduction in the biofilm formation by the $10 \mathrm{P}$. mirabilis isolates, but the highest antibiofilm effect was observed in samples grown in presence of IAN compared to those grown in IAA (Figure 8A). 


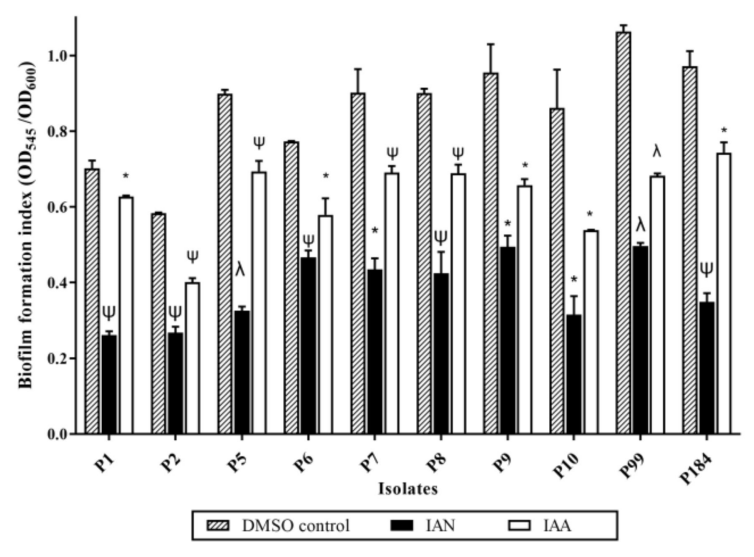

A

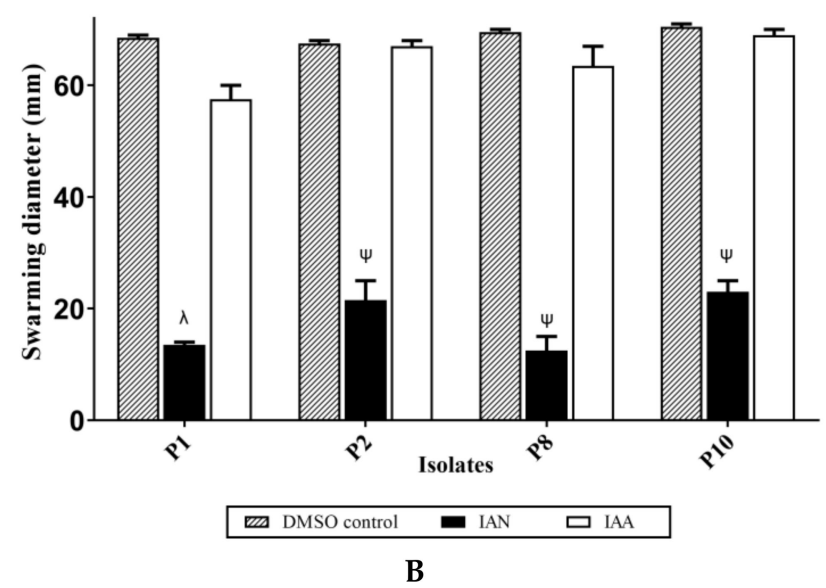

Figure 8. Effect of synthetic indole-3-acetonitrile (IAN) and indole-3-acetic acid (IAA) at concentration of $50 \mu \mathrm{g} / \mathrm{mL}$ on the virulence phenotype of P. mirabilis (A) Biofilm formation index of ten P. mirabilis isolates, (B) Swarming motility of four P. mirabilis isolates, Data represents the mean of at least 3 replicates, and error bars show standard error of the mean and statistical difference was evaluated by student's $t$-test ${ }^{*} p<0.05 ;{ }^{\psi} p<0.01{ }^{\lambda} p<0.001$ compared with DMSO control.

Motility behavior was assessed by the swarming motility assay on four P. mirabilis isolates. IAN (detected in Zch127 extract only) showed inhibitory effect on the swarming motility of P. mirabilis isolates compared to the controls (Figure 8B) while IAA failed to inhibit the swarming motility.

\section{Materials and Methods}

\subsection{Reagents and Standards}

All chemicals and solvents were purchased from Sigma-Aldrich (St. Louis, MO, USA), except L-tryptophan (Trp), indole-3-acetic acid (IAA), indole-3-lactic acid (ILA), and tryptamine (TAM), which were the products of Acros Organics (Morris Plains, NJ, USA), and indole-3-pyruvic acid (IPyA), which was purchased from Santa Cruz Biotechnology (Dallas, TX, USA). All chemicals and solvents used were analytical grade except those used in high-performance liquid chromatography (HPLC) and LC-MS which were of HPLC grade. Crude extracts stock $(50 \mathrm{mg} / \mathrm{mL}$ ) were prepared in 50\% DMSO. Stock solutions of extracts and dimethyl sulfoxide (DMSO) control were subsequently diluted into media to yield the concentrations that are indicated in each experiment.

\subsection{Clinical Strains and Growth Conditions}

The antivirulence activity of crude indole extracts were assessed against ten P. mirabilis isolates recovered from urinary tract infections. Isolates were obtained from Kasr -El Ainy Hospital in a previous study [5] after the approval of the Ethics Committee in the Faculty of Pharmacy- October University for Modern Sciences and Arts (MSA) with ethics approval number (M1/EC1/2016PD). The study was also approved by the Ethics Committee in the Faculty of Pharmacy- Cairo University with ethics approval number MI (1739). The bacteria were routinely cultured aerobically at $37^{\circ} \mathrm{C}$ in Luria-Bertani (LB) media. Susceptibility of these isolates to the respective antibiotics were carried out by disc diffusion method (Kirby-Bauer method) according to CLSI [28].

\subsection{Isolation of Bacteria from Soil, Identification, and Screening for Indole Production}

The rhizobacteria used in this study were isolated from the soil surrounding roots of plants in different locations in Egypt. Soil samples were transported in sterile polyethylene bags, secured between two ice packs to the laboratory [36].

One gram of soil sample was suspended in $20 \mathrm{~mL}$ of sterile saline and incubated at $30{ }^{\circ} \mathrm{C}$ and $200 \mathrm{rpm}$ for $30 \mathrm{~min}$. One milliliter of the soil suspension was then serially diluted (ten-fold) and cultured on nutrient agar followed by incubation at $30^{\circ} \mathrm{C}$ for two 
days [37]. Collected isolates were screened for the production of indole derivatives using the quantitative method developed by Bric et al. [38] with modifications. Briefly, overnight cultures of the tested isolates, grown in Trypticase Soy Broth (TSB) medium, were adjusted to $\mathrm{OD}_{600}$ of 1 then diluted 1:100 in fresh TSB supplemented with L-tryptophan to a final concentration of $0.5 \mathrm{mM}$. Flasks were incubated at $30^{\circ} \mathrm{C}$ with shaking (120 rpm) for 4 days. Quantitative estimation of indole derivatives in supernatants were carried out by the colorimetric assay using Salkowski's reagent [39]. Isolates showing high production of indole derivatives were identified by the conventional microbiological methods followed by molecular analysis based on their 16s $r R N A$ gene sequence. Target gene was amplified by the universal primers designed by Weisburg et al. [40] followed by sequencing using ABI 3730xl DNA Analyzer in Macrogen ${ }^{\circledR}$ (Seoul, South Korea). Gene sequences were compared to sequences in the NCBI database using the Basic Local Alignment Search Tool (BLAST). Genetic diversity between selected isolates was analyzed using Molecular Evolutionary Genetics Analysis version 6.0 (MEGA 6). The phylogenetic tree was constructed by the maximum parsimony method [41].

\subsection{Preparation of Crude Extracts from Enterobacter sp. Isolates}

Indole producing isolates were grown under the same conditions used in the preliminary screening for indole production. Supernatant was acidified to $\mathrm{pH} 2.5$ to 3.0 using $\mathrm{HCl}(1 \mathrm{~N})$. Extraction of the metabolites from the acidified supernatant was carried out by shaking with double volumes of ethyl acetate (EtOAc) and that was repeated twice. The EtOAc fractions were pooled and dried under vacuum in a rotary flash evaporator (Heidolph, Germany) at $45^{\circ} \mathrm{C}$. A stock solution of $50 \mathrm{mg} / \mathrm{mL}$ was prepared by dissolving dried extract in $50 \%$ DMSO [42].

\subsection{Determination of Minimum Inhibitory Concentration (MIC) of Crude Extract against P. mirabilis Isolates}

Crude extracts from the supernatant of the selected isolates, were tested against the P. mirabilis isolates to determine their MIC according to the Clinical and Laboratory Standards Institute [28] guidelines. Bacterial cultures were added at initial inoculum

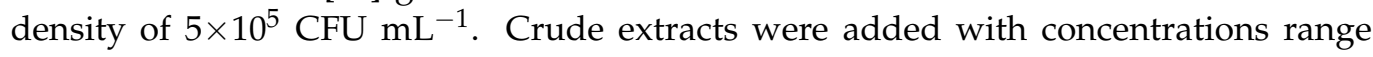
$0.01-5 \mathrm{mg} / \mathrm{mL}$.

The effect of the sub-MICs of crude extract on the growth of P. mirabilis was determined by turbidimetric assay. Briefly, overnight cultures of P. mirabilis clinical strains in LB were diluted to achieve turbidity equivalent to $\mathrm{OD}_{600}$ of 1 and then diluted 1:100 in LB broth supplemented with the extract in a final concentration of half the MIC. The culture was then incubated at $37^{\circ} \mathrm{C}$ with constant shaking at $250 \mathrm{rpm}$. Culture supplemented with DMSO at the same final concentration as the test was used as a control. The optical density of the respective bacterial growth at $600 \mathrm{~nm}$ was determined at different time intervals that ranged from 0 to $24 \mathrm{~h} \mathrm{[6]}$.

\subsection{Assessment of the Antivirulence Potential of Crude Extract against P. mirabilis}

\subsubsection{Effect on Biofilm Formation}

The biofilm forming ability of the P. mirabilis isolates was determined by the crystal violet assay [43]. After incubation, microbial growth was determined by measuring the turbidity at $600 \mathrm{~nm}\left(\mathrm{OD}_{\text {growth }}\right)$ and the biofilm biomass was measured colorimetrically at $545 \mathrm{~nm}\left(\mathrm{OD}_{\mathrm{CV}}\right)$. The biofilm formation was evaluated using a biofilm formation index [BFI]: $\left(\mathrm{OD}_{\mathrm{CV}}\right.$ Biofilm - $\mathrm{OD}_{\mathrm{CV}}$ Control)/OD growth [27]. Isolates were classified into nonadherent, weak, moderate and strong biofilm forming according to the semiquantitative classification of biofilm production as described by Naves et al. [44]. Effect of the extract on biofilm formation by P. mirabilis strains was estimated according to Labrecque et al. [45] with slight modifications. Briefly, overnight cultures of $P$. mirabilis strains were diluted to reach a cell density of $1.5 \times 10^{8} \mathrm{CFU} / \mathrm{mL}$ and then diluted to 1:50 in LB broth. In each well, $100 \mu \mathrm{L}$ of diluted cultures were added to equal volume of the extract at $2 \mathrm{X}$ of the 
required sub-MIC concentration in 96-well flat bottom polystyrene microtiter plate (Greiner Bio-one ${ }^{\circledR}$, Germany). Culture with DMSO and blank medium served as positive and negative controls, respectively. Plates were incubated at $37^{\circ} \mathrm{C}$ for $24 \mathrm{~h}$ without agitation. Biofilm was stained by crystal violet $(1 \%)$. Unbound stain was removed and the wells were washed with $200 \mu \mathrm{L}$ of sterile distilled water. The water was removed and the plates were air dried. Finally, stain was solubilized in glacial acetic acid (33\%).

\subsubsection{Effect on the Swarming and Swimming Behavior}

One milliliter of an overnight culture of $P$. mirabilis in LB broth was centrifuged and the resulting pellet was washed twice by $1 \mathrm{~mL}$ of saline $(0.9 \%)$, and finally suspended in saline to reach a concentration equivalent to $\mathrm{OD}_{600}$ of 1 . To test the effect of the extract on the swarming motility, five microliters of the adjusted suspension was pipetted onto the dry surface of LB plates ( $2 \%$ agar) containing sub-MIC of the extract. After $16 \mathrm{~h}$ of incubation at $37^{\circ} \mathrm{C}$, the diameter of the swarm circle was measured in mm and compared to motility on control plate containing equivalent concentration of DMSO to test plates [46].

For swimming assay, the adjusted overnight $P$. mirabilis cultures were stabbed into the center of a dried LB swimming agar plate $(0.4 \% \mathrm{w} / \mathrm{v}$ agar) with sub-MIC concentrations. After overnight incubation at $37^{\circ} \mathrm{C}$, the swimming zones diameters were measured in $\mathrm{mm}$ and the results were compared to control plates [47].

\subsubsection{Effect on Urease Production}

The effect of the extracts on the urease production by $P$. mirabilis was carried out using liquid Christensen's medium, with added urea at concentration of $20 \mathrm{~g} / \mathrm{L}$. Inoculum used was prepared as described previously (for swarming and swimming test). One hundred $\mu \mathrm{L}$ of microbial suspension were inoculated in $10 \mathrm{~mL}$ of the medium containing the extracts at sub-MIC and incubated for $3 \mathrm{~h}$ at $37^{\circ} \mathrm{C}$. After incubation, bacterial cells were removed by centrifugation and the change in color of supernatant was measured at wavelength $570 \mathrm{~nm}$ and compared to the color of the control without extract [48].

\subsubsection{Effect on the Minimum Inhibitory Concentration (MIC) of Antibiotics}

The effect of crude extract on bacterial sensitivity to antibiotics was determined by measuring the change in the MIC of antibiotics upon combination with extract. Antibiotics that belong to different classes were selected including ceftriaxone, amikacin and ciprofloxacin. MICs were determined by microbroth dilution method according to the Clinical and Laboratory Standards Institute guidelines [28]. MIC values were recorded in absence and presence of sub-MICs of crude extract. DMSO, equivalent to those present in crude extract, was added in the extract free wells. [6]. The synergistic and antagonistic activity of this combination was reflected by decrease and increase in MIC values, respectively, compared to untreated isolates.

\subsection{HPLC and LC-MS/MS Analysis of the Microbial Extract}

Indole compounds in the EtOAc extract were analyzed using Waters ${ }^{\circledR}$ 600E HPLC (Milford, MA, USA) equipped with a Nucleosil 120-5 $\mathrm{C}_{18}$ reverse column (5 $\mathrm{mm}, 250 \mathrm{U} 4$ $\mathrm{mm}$ ) from Richard Scientific (Novato, CA, USA). Detection wavelength was $280 \mathrm{~nm}$, and confirmed by retention time and co-migration (spiking with an authentic standard). Further verification and quantification of indole derivatives were performed using authentic standards of Trp, indole-3-acetic acid (IAA), indole-3-ethanol (TOL), indole-3-pyruvic acid (IPA), indole-3-acetamide (IAM), indole-3-acetonitrile (IAN), tryptamine (TAM), and indole-lactic acid (ILA). The authentic indole compounds were used in concentration of $100 \mu \mathrm{M}$ each, except IPA which were used at $200 \mu \mathrm{M}$ [49]. The concentration was estimated by the determination of the area under the curve (AUC).

Concentration of the unknown $=$

(AUC of the unknown sample - AUC of the standard) $\times$ Conc. of the standard AUC of the standard 
The Enterobacter sp. extracts were analyzed using liquid chromatography-mass spectrometry (LC-MS). Electrospray Ionization Mass Spectrometry (ESI-MS) positive and negative ion acquisition mode were carried out on a Waters ${ }^{\circledR}$ Xevo TQD (Milford, MA, USA), coupled to mass spectrometer Column: (ACQUITY UPLC-BEH C ${ }_{18} 1.7 \mu \mathrm{m}-2.1 \times 50 \mathrm{~mm}$ column) with flow rate of $0.2 \mathrm{~mL} / \mathrm{min}$. Solvent system: consisted of gradient mobile phase (A): Water containing $0.1 \%$ formic acid, (B): Methanol containing $0.1 \%$ formic acid. The sample $(100 \mu \mathrm{g} / \mathrm{mL})$ solution was dissolved in methanol, and filtered then subjected to LC-MS analysis [29].

The parameters for analysis were carried out using positive and negative ion mode as follows: source temperature $150{ }^{\circ} \mathrm{C}$, cone voltage $30 \mathrm{eV}$, capillary voltage $3 \mathrm{kV}$, desolvation temperature $440{ }^{\circ} \mathrm{C}$, cone gas flow $50 \mathrm{~L} / \mathrm{h}$, and desolvation gas flow $900 \mathrm{~L} / \mathrm{h}$. Full scan MS was between $m / z$ 100-1000. The peaks and spectra were processed using the Masslynx 4.1 software and tentatively identified by comparing its retention time (Rt) and mass spectrum, and mass fragmentation pattern reported in Mass Bank (http:/ / www.massbank.jp), and PubChem (https:/ / pubchem.ncbi.nlm.nih.gov/) (accessed on 15 August 2020).

\subsection{Statistical Analysis}

All experiments were repeated at least three times. Statistical analysis of the data obtained from the studies was conducted with GraphPad Prism version 8.0.0 for Windows, (San Diego, CA, USA) software. Statistical tests used were Student's $t$-test, and two-way ANOVA (analysis of variance) where appropriate. $p \leq 0.05$ was considered as significant.

\section{Conclusions}

The current work has revealed that indole derivatives extracted from the rhizobacteria Enterobacter sp. have promising antivirulence and antibiofilm activity against $P$. mirabilis which is one of the important causative agents of complicated urinary tract infections. The results of the HPLC and LC-MS analysis of the crude extract suggest that there is more than one metabolic pathway for production of indole acetic acid in Enterobacter sp. The metabolic pattern of Enterobacter sp. differs according to the soil environment from which it was isolated. The IAN detected in the Zch127 could be responsible for the significant anti-swarming and anti-urease activity of this extract compared to Cbg70 extract.

Supplementary Materials: The following are available online at https:/ /www.mdpi.com/article/10 .3390 /antibiotics10040363/s1, Table S1: Concentration of IAA produced by the bacterial isolates after 4 days of incubation in trypticase soy broth supplemented with $100 \mu \mathrm{g} / \mathrm{mL}(0.5 \mathrm{mM})$ tryptophan, Figure S1: Evolutionary relationships between Enterobacter sp. Cbg70 and Zch127 with related strains, Figure S2: Effect of culture extract of Cbg70 on the growth of 10 P. mirabilis isolates, Figure S3: Effect of culture extract of Zch127 on the growth of 10 P. mirabilis isolates, Figure S4 and S5: The effect of extract Zch127 on P. mirabilis isolates swarming motility, Figure S6: The effect of extract Zch127 on P. mirabilis isolates swimming motility, Figure S7: LC-MS chromatograms from ESI positive and negative modes of the extracted compounds, Figure S8: Liquid chromatography-mass spectrometry (LC-MS) fragmentation analysis of targeted indole derivatives in Cbg70 at positive mode, Figure S9: Liquid chromatography-mass spectrometry (LC-MS) fragmentation analysis of targeted indole derivatives in Cbg70 at negative mode, Figure S10: Liquid chromatography-mass spectrometry (LC-MS) fragmentation analysis of targeted indole derivatives in Zch127 at positive mode, Figure S11: Liquid chromatography-mass spectrometry (LC-MS) fragmentation analysis of the targeted indole derivatives in Zch127 at negative mode.

Author Contributions: Conceptualization, R.W., A.S.A. and M.A.R.; Formal analysis, M.A.A., R.W., A.S.A. and M.A.R.; Methodology, M.A.A.; Software, M.A.A.; Supervision, R.W., A.S.A. and M.A.R.; Writing—original draft, M.A.A.; Writing—review \& editing, R.W., A.S.A. and M.A.R. All authors have read and agreed to the published version of the manuscript.

Funding: Part of the article processing charges (APC) for publishing this work was funded by Cairo University. 
Institutional Review Board Statement: The study was conducted according to the guidelines of the Declaration of Helsinki, and approved by the Ethics Committee in the Faculty of Pharmacy- Cairo University with ethics approval number MI (1739) and by the Ethics Committee in the Faculty of Pharmacy- October University for Modern Sciences and Arts (MSA) with ethics approval number (M1/EC1/2016PD).

Informed Consent Statement: Informed consent was obtained from all subjects involved in study.

Data Availability Statement: Data is contained within the article or supplementary material.

Conflicts of Interest: The authors declare no conflict of interest.

\section{References}

1. E Nicolle, L. Catheter associated urinary tract infections. Antimicrob. Resist. Infect. Control. 2014, 3, 23. [CrossRef]

2. Ranjbar-Omid, M.; Arzanlou, M.; Amani, M.; Al-Hashem, S.K.S.; Mozafari, N.A.; Doghaheh, H.P. Allicin from garlic inhibits the biofilm formation and urease activity of Proteus mirabilis in vitro. FEMS Microbiol. Lett. 2015, 362, 9. [CrossRef]

3. Wasfi, R.; Hamed, S.M.; Amer, M.A.; Fahmy, L.I. Proteus mirabilis Biofilm: Development and Therapeutic Strategies. Front. Cell. Infect. Microbiol. 2020, 10, 414. [CrossRef]

4. Dandrea, M.M.; Literacka, E.; Zioga, A.; Giani, T.; Baraniak, A.; Fiett, J.; Sadowy, E.; Tassios, P.T.; Rossolini, G.M.; Gniadkowski, M.; et al. Evolution and Spread of a Multidrug-Resistant Proteus mirabilis Clone with Chromosomal AmpC-Type Cephalosporinases in Europe. Antimicrob. Agents Chemother. 2011, 55, 2735-2742. [CrossRef] [PubMed]

5. Wasfi, R.; Abdellatif, G.R.; Elshishtawy, H.M.; Ashour, H.M. First-time characterization of viable but non-culturable Proteus mirabilis: Induction and resuscitation. J. Cell. Mol. Med. 2020, 24, 2791-2801. [CrossRef]

6. Lee, J.-H.; Kim, Y.-G.; Cho, M.H.; Kim, J.-A.; Lee, J. 7-fluoroindole as an antivirulence compound against Pseudomonas aeruginosa. FEMS Microbiol. Lett. 2012, 329, 36-44. [CrossRef] [PubMed]

7. Lee, J.-H.; Wood, T.K.; Lee, J. Roles of Indole as an Interspecies and Interkingdom Signaling Molecule. Trends Microbiol. 2015, 23, 707-718. [CrossRef] [PubMed]

8. Lee, J.-H.; Lee, J. Indole as an intercellular signal in microbial communities. FEMS Microbiol. Rev. 2010, 34, 426-444. [CrossRef] [PubMed]

9. Lee, J.-H.; Cho, M.H.; Lee, J. 3-Indolylacetonitrile DecreasesEscherichia coliO157:H7 Biofilm Formation andPseudomonas aeruginosaVirulence. Environ. Microbiol. 2010, 13, 62-73. [CrossRef]

10. Lee, J.-H.; Kim, Y.-G.; Kim, C.-J.; Lee, J.-C.; Cho, M.H.; Lee, J. Indole-3-acetaldehyde from Rhodococcus sp. BFI 332 inhibits Escherichia coli O157:H7 biofilm formation. Appl. Microbiol. Biotechnol. 2012, 96, 1071-1078. [CrossRef]

11. Nikaido, E.; Giraud, E.; Baucheron, S.; Yamasaki, S.; Wiedemann, A.; Okamoto, K.; Takagi, T.; Yamaguchi, A.; Cloeckaert, A.; Nishino, K. Effects of indole on drug resistance and virulence of Salmonella enterica serovar Typhimurium revealed by genome-wide analyses. Gut Pathog. 2012, 4, 5. [CrossRef]

12. Lee, J.-H.; Cho, H.S.; Kim, Y.; Kim, J.-A.; Banskota, S.; Cho, M.H.; Lee, J. Indole and 7-benzyloxyindole attenuate the virulence of Staphylococcus aureus. Appl. Microbiol. Biotechnol. 2013, 97, 4543-4552. [CrossRef] [PubMed]

13. Choi, S.; Kim, Y.; Oh, S.; Chun, T.; Kim, S. Inhibitory effect of skatole (3-methylindole) on enterohemorrhagic Escherichia coli O157:H7 ATCC 43894 biofilm formation mediated by elevated endogenous oxidative stress. Lett. Appl. Microbiol. 2014, 58, 454-461. [CrossRef] [PubMed]

14. Palaniyandi, S.A.; Yang, S.H.; Zhang, L.; Suh, J.-W. Effects of actinobacteria on plant disease suppression and growth promotion. Appl. Microbiol. Biotechnol. 2013, 97, 9621-9636. [CrossRef] [PubMed]

15. Kutáček, M.; Procházka, Ž.; Grünberger, D. Biogenesis of Ascorbigen, 3-Indolylacetonitrile and Indole-3-carboxylic Acid from D,L-Tryptophan-3-14C in Brassica oleracea L. Nat. Cell Biol. 1960, 187, 61-62. [CrossRef] [PubMed]

16. Higdon, J.V.; Delage, B.; Williams, D.E.; Dashwood, R.H. Cruciferous vegetables and human cancer risk: Epidemiologic evidence and mechanistic basis. Pharmacol. Res. 2007, 55, 224-236. [CrossRef]

17. Fan, S.; Meng, Q.; Saha, T.; Sarkar, F.H.; Rosen, E.M. Low Concentrations of Diindolylmethane, a Metabolite of Indole-3-Carbinol, Protect against Oxidative Stress in a BRCA1-Dependent Manner. Cancer Res. 2009, 69, 6083-6091. [CrossRef]

18. Ladha, J.K.; Barraquio, W.L.; Watanabe, I. Isolation and identification of nitrogen-fixing Enterobacter cloacae and Klebsiella planticola associated with rice plants. Can. J. Microbiol. 1983, 29, 1301-1308. [CrossRef]

19. Tsuda, K.; Kosaka, Y.; Tsuge, S.; Kubo, Y.; Horino, O. Evaluation of the Endophyte Enterobacter cloacae SM10 Isolated from Spinach Roots for Biological Control against Fusarium Wilt of Spinach. J. Gen. Plant Pathol. 2001, 67, 78-84. [CrossRef]

20. Panigrahi, S.; Mohanty, S.; Rath, C. Characterization of endophytic bacteria Enterobacter cloacae MG00145 isolated from Ocimum sanctum with Indole Acetic Acid (IAA) production and plant growth promoting capabilities against selected crops. S. Afr. J. Bot. 2020, 134, 17-26. [CrossRef]

21. Pratt, L.A.; Kolter, R. Genetic analysis ofEscherichia colibiofilm formation: Roles of flagella, motility, chemotaxis and type I pili. Mol. Microbiol. 1998, 30, 285-293. [CrossRef] [PubMed]

22. Packiavathy, I.A.S.V.; Priya, S.; Pandian, S.K.; Ravi, A.V. Inhibition of biofilm development of uropathogens by curcumin-An anti-quorum sensing agent from Curcuma longa. Food Chem. 2014, 148, 453-460. [CrossRef] [PubMed] 
23. Son, J.-S.; Lee, S.-J.; Jun, S.Y.; Yoon, S.J.; Kang, S.H.; Paik, H.R.; Kang, J.O.; Choi, Y.-J. Antibacterial and biofilm removal activity of a podoviridae Staphylococcus aureus bacteriophage SAP-2 and a derived recombinant cell-wall-degrading enzyme. Appl. Microbiol. Biotechnol. 2010, 86, 1439-1449. [CrossRef] [PubMed]

24. Saeed, A.; Bosch, A.; Bettiol, M.; González, D.L.N.; Erben, M.F.; Lamberti, Y. Novel Guanidine Compound against MultidrugResistant Cystic Fibrosis-Associated Bacterial Species. Molecules 2018, 23, 1158. [CrossRef] [PubMed]

25. Lee, J.; Attila, C.; Cirillo, S.L.G.; Cirillo, J.D.; Wood, T.K. Indole and 7-hydroxyindole diminish Pseudomonas aeruginosa virulence. Microb. Biotechnol. 2008, 2, 75-90. [CrossRef] [PubMed]

26. Turner, D.N.; Edwards, L.; Kornienko, A.; Frolova, L.V.; Rogelj, S. Synergistic action of substituted indole derivatives and clinically used antibiotics against drug-resistant bacteria. Futur. Microbiol. 2020, 15, 579-590. [CrossRef]

27. Yaikhan, T.; Chuerboon, M.; Tippayatham, N.; Atimuttikul, N.; Nuidate, T.; Yingkajorn, M.; Tun, A.W.; Buncherd, H.; Tansila, N. Indole and Derivatives Modulate Biofilm Formation and Antibiotic Tolerance of Klebsiella pneumoniae. Indian J. Microbiol. 2019, 59, 460-467. [CrossRef]

28. CLSI. Clinical and Laboratory Standards Institute. Performance Standards for Antimicrobial Susceptibility Testing; Twenty-First Informational Supplement; CLSI Document M100-S21; The Clinical \& Laboratory Standards Institute: Wayne, PA, USA, 2018.

29. Mujahid Sasikala, C.; Ramana, C.V. Production of indole-3-acetic acid and related indole derivatives from L-tryptophan by Rubrivivax benzoatilyticus JA2. Appl. Microbiol. Biotechnol. 2011, 89, 1001-1008. [CrossRef] [PubMed]

30. Lin, G.-H.; Chang, C.-Y.; Lin, H.-R. Systematic profiling of indole-3-acetic acid biosynthesis in bacteria using LC-MS/MS. J. Chromatogr. B 2015, 988, 53-58. [CrossRef]

31. Qiu, Y.-Q. KEGG Pathway Database. Encycl. Syst. Biol. 2013, 1068-1069. [CrossRef]

32. Jasim, B.; John, C.J.; Shimil, V.; Jyothis, M.; Radhakrishnan, E. Studies on the factors modulating indole-3-acetic acid production in endophytic bacterial isolates from Piper nigrum and molecular analysis of ipdc gene. J. Appl. Microbiol. 2014, 117, 786-799. [CrossRef] [PubMed]

33. Harris, D.M.; Berrué, F.; Kerr, R.; Patten, C.L. Metabolomic analysis of indolepyruvate decarboxylase pathway derivatives in the rhizobacterium Enterobacter cloacae. Rhizosphere 2018, 6, 98-111. [CrossRef]

34. Bruto, M.; Prigent-Combaret, C.; Muller, D.; Moënne-Loccoz, Y. Analysis of genes contributing to plant-beneficial functions in plant growth-promoting rhizobacteria and related Proteobacteria. Sci. Rep. 2014, 4, srep06261. [CrossRef] [PubMed]

35. Kobayashi, M.; Suzuki, T.; Fujita, T.; Masuda, M.; Shimizu, S. Occurrence of enzymes involved in biosynthesis of indole-3-acetic acid from indole-3-acetonitrile in plant-associated bacteria, Agrobacterium and Rhizobium. Proc. Natl. Acad. Sci. USA 1995, 92, 714-718. [CrossRef] [PubMed]

36. Ogunmwonyi, I.N.; Igbinosa, E.; Aiyegoro, O.; Odjadjare, E. Microbial analysis of different top soil samples of selected site in Obafemi Awolowo University, Nigeria. Sci. Res. Essays 2008, 3, 120-124.

37. Lwin, K.M.; Myint, M.M.; Tar, T.; Aung, W.Z.M. Isolation of Plant Hormone (Indole-3-Acetic Acid-IAA) Producing Rhizobacteria and Study on Their Effects on Maize Seedling. Eng. J. 2012, 16, 137-144. [CrossRef]

38. Bric, J.M.; Bostock, R.M.; Silverstone, S.E. Rapid In Situ Assay for Indoleacetic Acid Production by Bacteria Immobilized on a Nitrocellulose Membrane. Appl. Environ. Microbiol. 1991, 57, 535-538. [CrossRef] [PubMed]

39. Aziz, K.; Nawaz, M.; Nazir, J.; Anjum, A.; Yaqub, T.; Ahmad, M.-u.-D.; Rehman, M.U.; Aziz, G.; Khan, M. Isolation, characterization and effect of auxin producing bacteria on growth of Triticum aestivum. J. Anim. Plant Sci. 2015, 25, $1003-1007$.

40. Weisburg, W.G.; Barns, S.M.; Pelletier, D.A.; Lane, D.J. 16 S ribosomal DNA amplification for phylogenetic study. J. Bacteriol. 1991, 173, 697-703. [CrossRef]

41. Tamura, K.; Stecher, G.; Peterson, D.; Filipski, A.; Kumar, S. MEGA6: Molecular Evolutionary Genetics Analysis Version 6.0. Mol. Biol. Evol. 2013, 30, 2725-2729. [CrossRef]

42. Goswami, D.; Thakker, J.N.; Dhandhukia, P.C. Simultaneous detection and quantification of indole-3-acetic acid (IAA) and indole-3-butyric acid (IBA) produced by rhizobacteria from l-tryptophan (Trp) using HPTLC. J. Microbiol. Methods 2015, 110, 7-14. [CrossRef]

43. O'Toole, G.A. Microtiter Dish Biofilm Formation Assay. J. Vis. Exp. 2011, 2437, e2437. [CrossRef] [PubMed]

44. Naves, P.; Del Prado, G.; Huelves, L.; Gracia, M.; Ruiz, V.; Blanco, J.; Rodríguez-Cerrato, V.; Ponte, M.; Soriano, F. Measurement of biofilm formation by clinical isolates ofEscherichia coliis method-dependent. J. Appl. Microbiol. 2008, 105, 585-590. [CrossRef] [PubMed]

45. Labrecque, J.; Bodet, C.; Chandad, F.; Grenier, D. Effects of a high-molecular-weight cranberry fraction on growth, biofilm formation and adherence of Porphyromonas gingivalis. J. Antimicrob. Chemother. 2006, 58, 439-443. [CrossRef]

46. Aygül, A.; Kibar, F.; Çıragil, P. Quercetin and Cinnamaldehyde Show Antipathogenic Activity Against Proteus mirabilis Isolates: Inhibition of Swarming Motility and Urease Activity. Flora J. Infect. Dis. Clin. Microbiol. 2020, 25, 76-83. [CrossRef]

47. Abdel-Baky, R.M.; Ali, M.A.; Abuo-Rahma, G.E.-D.A.A.; Abdelaziz, N. Inhibition of Urease Enzyme Production and some Other Virulence Factors Expression in Proteus mirabilis by N-Acetyl Cysteine and Dipropyl Disulphide. Adv. Exp. Med. Biol. 2017, 973, 99-113. [CrossRef]

48. Nicolosi, D.; Tempera, G.; Genovese, C.; Furneri, P.M. Anti-Adhesion Activity of A2-type Proanthocyanidins (a Cranberry Major Component) on Uropathogenic E. coli and P. mirabilis Strains. Antibiotics 2014, 3, 143-154. [CrossRef]

49. Chung, K.-R.; Shilts, T.; Ertã $\frac{1}{4}$ Rk ÃœMran; Timmer, L.W.; Ueng, P.P. Indole derivatives produced by the fungusColletotrichum acutatumcausing lime anthracnose and postbloom fruit drop of citrus. FEMS Microbiol. Lett. 2003, 226, 23-30. [CrossRef] 